\title{
Estimation of Material Losses and the Effects of Cassava at Different Maturity Stages on Garification Index
}

\author{
Sobowale $\mathrm{SS}^{1 *}$, Awonorin $\mathrm{SO}^{2}$, Shittu $\mathrm{TA}^{2}$, Oke $\mathrm{MO}^{3}$ and Adebo $\mathrm{OA}^{4}$ \\ ${ }^{1}$ Department of Food Technology, Moshood Abiola Polytechnic, Abeokuta, Ogun State, Nigeria \\ ${ }^{2}$ Department of Food Science and Technology, Federal University of Agriculture, Abeokuta, Ogun State, Nigeria \\ ${ }^{3}$ Department of Food Science and Engineering, Ladoke Akintola University of Technology, Ogbomoso, Oyo State, Nigeria \\ ${ }^{4}$ Department of Biotechnology and Food Technology, University of Johannesburg, Doornfontein 2028, South Africa
}

\begin{abstract}
Gari, a West African staple food was processed using fresh cassava tubers (TMS 30572 cultivar). Material losses and garification rate index as affected by the cassava ages of maturity, fermentation days and processing stages were determined. The material losses and yield of $g a r i$ from 9,12 and 15 months old cassava plants at different processing stages and fermentation days were evaluated. Results showed that the average peeling loss at different maturity ages ranged between 21 and $28.86 \%$ while percentage grating loss ranged from 3.71 to $5 \%$. Likewise, estimated percentage dewatering/fermentation loss ranged from 25.55 to $30 \%$, while sieving loss ranged from 4.24 to $5.14 \%$. Garification losses ranged from 17.45 to $19.79 \%$ with an average gari yield between 19.86 and $23.68 \%$. Cassava of 15 months maturity age generally produced higher yields of gari than those harvested early. The mean garification conversion rate achieved was $22 \%(0.22, \mathrm{wt} / \mathrm{wt})$.
\end{abstract}

Keywords: Cassava; Material losses; Yield; Gari; Garification index

\section{Introduction}

Cassava (Manihot esculenta crantz) is one of the major root tubers produced in the forest zones of Nigeria, with yields as high as 38 million metric tons per annum [1]. It is a major source of staple food in West Africa, providing basic diet to millions of its teeming population across the different socio-economic classes. Due to its relative high moisture and cyanide content, cassava needs to be converted into suitable forms with longer shelf life and lower cyanide levels [2,3]. Different forms in which the processed root exists includes cassava bread, wet chips, elubo, lafun, cassava starch, roasted/boiled cassava, fufu (akpu) and gari $[4,5]$.

In Nigeria, similar to other West African countries, over $70 \%$ of the cassava yield is processed into gari, a staple and convenient food [6]. It is the major form in which cassava is consumed in West Africa. Gari is a fermented roasted granule prepared from peeled, grated and fermented cassava root through a series of processing steps [7]. The conventional method of producing this involves peeling and grating the fresh roots. The grated pulp is then fermented for one to five days. Subsequently, the pulp is compressed to reduce its moisture content, after which it is sieved and fried in heated pans. A dash of palm oil may during grating or at the point of garifying to prevent burning, producinga yellowish-gari is distinct from white-gari in which no oil is added. This is either consumed immediately or further processed into various forms that combine diversity, convenience and nutritional value $[8,9]$.

The traditional method of processing gari is an arduous, intricate and tedious operation. This requires a good understanding of combination factors which affects the quality and yield of the gari produced [10]. The inability to control moisture content as related to particle size and the exposure of processors to heat and fumes have been major mitigating factors reducing the efficiency of the traditional processing methods.

With the current food crisis in most part of the world and the potential of gari to substantially address calorie inadequacy of millions of people in Africa [11], it is imperative to maximize the yield of gari processing systems. This will ensure a comprehensive process analysis, to pinpoint factors causing material losses, as a guide in redesigning the garification process to minimize losses. This is vital for the development and assessment of new processing technologies [12]. Therefore, the purpose of this work was to establish a standard measure, to quantify the various losses and then determine the garification rate index associated with gari processing, using a locally fabricated electromechanical garifier.

\section{Materials and Methods}

\section{Processing of cassava tubers into gari}

The method described by Achinewhu, et al. [12] and Akingbala, et al. [13] was largely adopted. Fresh cassava tubers of the TMS 30572 cultivar were harvested at maturity ages of 9,12 and 15 months. They were sorted according to size, weight and shape by visual assessment. $70 \mathrm{~kg}$ of between 300-400 pieces of each maturity age of fresh cassava tubers were selected. There were respectively peeled, washed, drained and grated in a mechanized commercial grater. The grated pulp (mash) was loaded into jute bags and tied with a string. The mash was left to naturally ferment for a period of $0,1,2,3,4,5$, and 6 days at ambient temperature before pressing out the juice with hydraulic press. The pressed out mash (cake) were manually crushed and sieved $(1.50 \mathrm{~mm}$ mesh) to remove fibers. The starchy granules obtained were analyzed at different fermentation days and $1 \mathrm{~kg}$ from each of the samples was garified at a steady state in an electro-mechanical gari roaster developed locally with a capacity of $5 \mathrm{~kg} / \mathrm{h}$ and functional efficiency of $80 \%$. The machine (Figure 1) was operated at a constant stirring rate and allowed for gelatinization at $20 \mathrm{sec}$ interval. This process is called garification as it dextrinizes the starch and dries the granules. The gari produced

*Corresponding author: Sobowale SS, Department of Food Technology, Moshood Abiola Polytechnic, Abeokuta, Ogun State, Nigeria, Tel: +2348033791755; Email: sobowale.sam@gmail.com

Received December 02, 2015; Accepted December 28, 2015; Published January 05, 2016

Citation: Sobowale SS, Awonorin SO, Shittu TA, Oke MO, Adebo OA (2016) Estimation of Material Losses and the Effects of Cassava at Different Maturity Stages on Garification Index. J Food Process Technol 7: 554 doi:10.4172/2157-7110.1000554

Copyright: ( 2016 Sobowale SS, et al. This is an open-access article distributed under the terms of the Creative Commons Attribution License, which permits unrestricted use, distribution, and reproduction in any medium, provided the original author and source are credited. 
Citation: Sobowale SS, Awonorin SO, Shittu TA, Oke MO, Adebo OA (2016) Estimation of Material Losses and the Effects of Cassava at Different Maturity Stages on Garification Index. J Food Process Technol 7: 554. doi:10.4172/2157-7110.1000554

Page 2 of 5

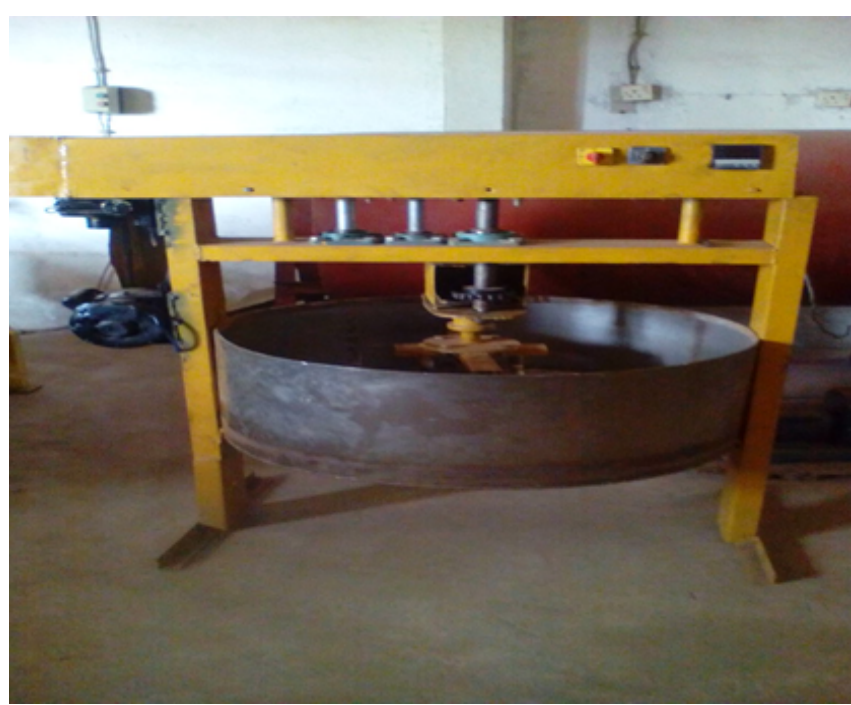

Figure 1: Electro-mechanical gari roaster

was air dried, cooled and packaged in polyethylene bags for further processing and analysis.

\section{Material losses}

Material losses comprise of both heat and mass transfer, occurring at all the stages of processing. The losses at each processing stage were determined using the difference in the weight of material recovered before and after each stage [14]. This was then subsequently calculated as a percentage of the initial weight of the fresh cassava. Based on this, the individual percentage losses [Peeling $\left(\mathrm{L}_{\mathrm{P}}\right)$, Grating $\left(\mathrm{L}_{\mathrm{G}}\right)$, Dewatering/Fermentation $\left(\mathrm{L}_{\mathrm{D}}\right)$, Sifting $\left(\mathrm{L}_{\mathrm{s}}\right)$ and Garifying $\left.\left(\mathrm{L}_{\mathrm{R}}\right)\right]$ were calculated using Eq. (1)-(5).

$$
\begin{aligned}
& \mathrm{L}_{\mathrm{p}}=\left(\mathrm{W}_{1}-\mathrm{W}_{2}\right) / \mathrm{W}_{1} \times 100 \\
& \mathrm{~L}_{\mathrm{G}}=\left(\mathrm{W}_{2}-\mathrm{W}_{3}\right) / \mathrm{W}_{1} \times 100 \\
& \mathrm{~L}_{\mathrm{D}}=\left(\mathrm{W}_{3}-\mathrm{W}_{4}\right) / \mathrm{W}_{1} \times 100 \\
& \mathrm{~L}_{\mathrm{s}}=\left(\mathrm{W}_{4}-\mathrm{W}_{5}\right) / \mathrm{W}_{1} \times 100 \\
& \mathrm{~L}_{\mathrm{R}}=\left(\mathrm{W}_{5}-\mathrm{W}_{6}\right) / \mathrm{W}_{1} \times 100
\end{aligned}
$$

where $\mathrm{W}_{1}$ is the initial weight of fresh cassava tubers $(\mathrm{kg}), \mathrm{W}_{2}$ is the weight of peeled tubers $(\mathrm{kg}), \mathrm{W}_{3}$ is the weight of wet mash collected from the grater $(\mathrm{kg}), \mathrm{W}_{4}$ is the weight of cassava cake after fermentation and dewatering $(\mathrm{kg}), \mathrm{W}_{5}$ is the weight of sifted granule $(\mathrm{kg})$ and $\mathrm{W}_{6}$ is the weight of the garified sample $(\mathrm{kg})$.

\section{Determination of the percentage yield of garification}

The total loss for each age of maturity at different fermentation periods were obtained by totaling the losses in Eq. (1)-(5). Hence, the total amount of gari obtained, expressed as a percentage of the fresh cassava roots is calculated as follows;

$\%$ yield of gari $=$ mass of gari $/$ mass of cassava that produced the gari $\times 100$

Mean values of the losses were also calculated. Therefore, from the obtained results, a relationship between the initial weight of fresh tubers $\left(\mathrm{W}_{1}\right)$ and gari yield was established thus:

$$
\mathrm{W}=\mathrm{W}_{1} \mathrm{~K}
$$

Where $\mathrm{W}$ is the weight of yield of gari $(\mathrm{kg})$ and $\mathrm{K}$ is a constant [garification conversion rate $(\mathrm{wt} / \mathrm{wt})$ ].

\section{Data analysis}

The statistical analysis of the data was conducted using MATLAB commercial software package [Version 7.10.0 (R2010a), Neural Works Professional II/Plus, Neural Ware, Pittsburg, USA]. All experimental data obtained were subjected to analysis of variance (ANOVA) using nonlinear regression model (NLR) procedure of Statistical Analysis System Institute (SAS, 2003). Means were compared at $5 \%$ significance level using Duncan's multiple range test, DMRT [15].

\section{Results and Discussion}

The estimated material losses at different processing stages and the final yield of gari from cassava ages of maturity (9, 12 and 15 months) and days of fermentation (0-6 days) are shown in Figures 2-8. Likewise, the effects of processing variables on the moisture contents are presented in Figures 9-11. The average peeling losses for cassava of 9 months maturity age was $26.86 \%$, the estimated percentage dewatering/ fermentation loss ranged from 25.50 to $25.57 \%$. The sieving loss ranged from 5.12 to $5.14 \%$, while the value of garification losses ranged from 17.45 to $17.57 \%$. The total loss was recorded to be between 79.93 and $80.14 \%$ with an average yield of gari ranging between 20.07 and $19.86 \%$. The average peeling loss from 12 months cassava age of maturity was $22.43 \%$. The percentage grating loss was $3.86 \%$, while the percentage

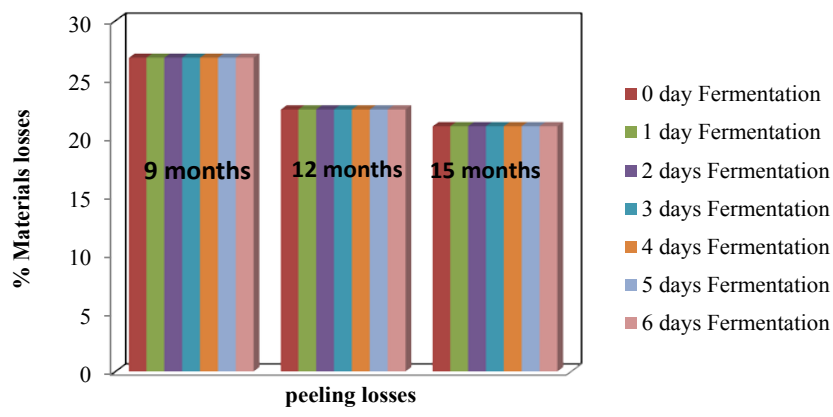

Figure 2: Estimated \% peeling losses at different ages of cassava and fermentation days.

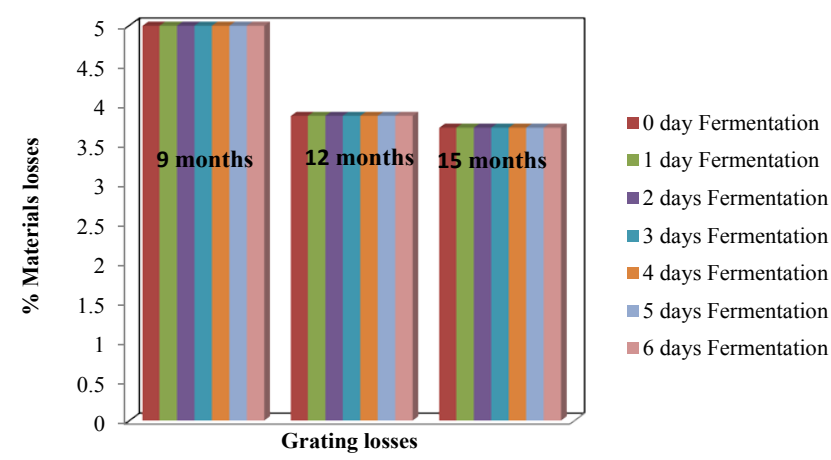

Figure 3: Estimated \% grating losses at different ages of cassava and fermentation days. 


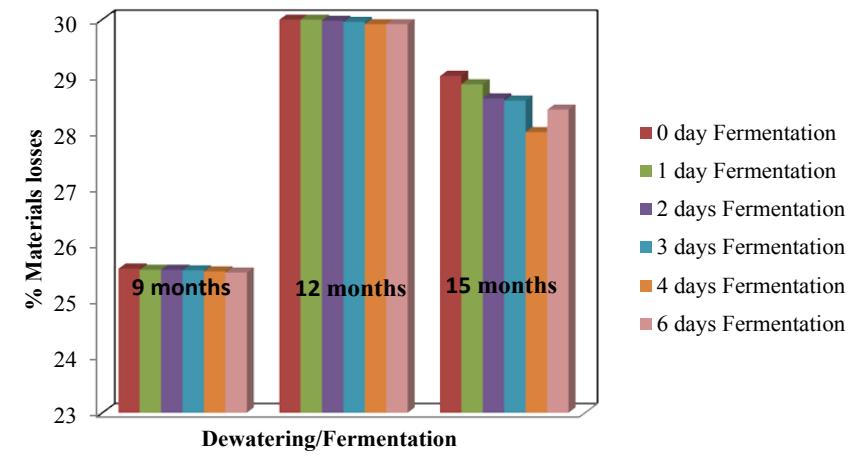

Figure 4: Estimated \% dewatering/fermentation losses at different ages of cassava and fermentation days.

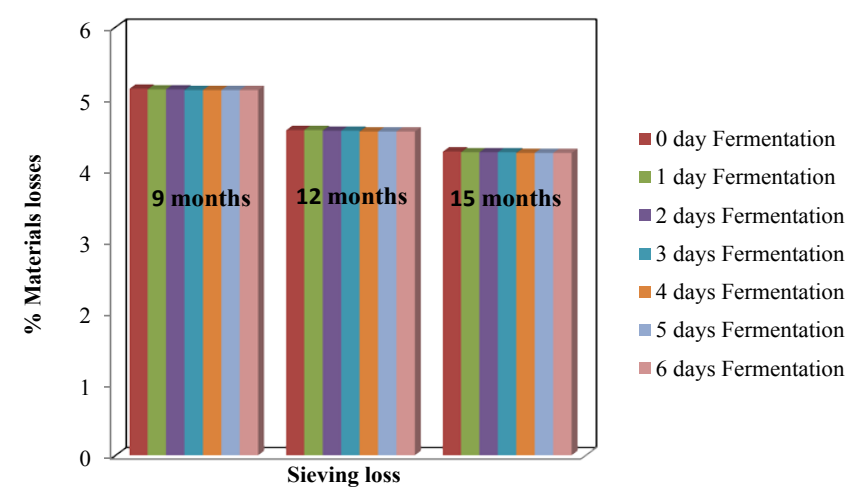

Figure 5: Estimated \% sieving losses at different ages of cassava and fermentation days.

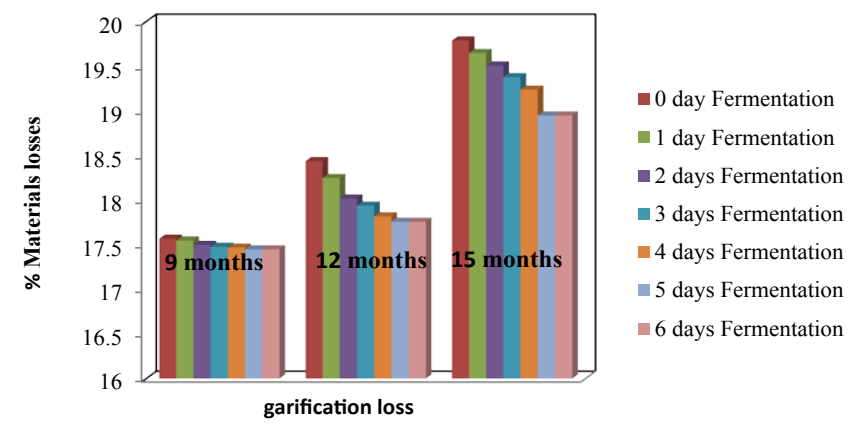

Figure 6: Estimated \% garification losses at different ages of cassava and fermentation days.

dewatering/fermentation loss ranged from 29.92 to $30 \%$. The sieving loss ranged from 4.54 to $4.56 \%$, while the garification losses ranged from 17.76 to $18.44 \%$. The total loss was estimated to be between 78.51 and $79.29 \%$ with an average yield of gari ranging between 21.49 and $20.71 \%$. The average peeling loss from 15 months cassava maturity age was $21 \%$. The grating loss was $3.71 \%$, while the estimated percentage dewatering/fermentation loss ranged from 28.42 to $29 \%$. The sieving loss ranged from 4.24 to $4.26 \%$, while the garification losses ranged from 18.95 to $19.79 \%$. The estimated total loss was between 76.32 and $77.76 \%$ with an average yield of gari ranging between 23.68 and $22.24 \%$.
The results from this study revealed that greater losses were recorded during the peeling, dewatering/fermentation and garification stages of processing, while grating and sieving had the lowest losses. According to Amoah, et al. [14], peeling requires the removal of the outer root cortex which contains the toxic cyanide, rotten portions and stumps. Alongside this, some considerable dry matter is also lost. The amount and quantity of these materials lost, however largely depends on cultivar type, peeling efficiency and quality of the cassava tubers. These peels make up about $10-15 \%$ of the tuber, but $25-30 \%$ losses is associated with hand peeling Opara [3] while its about $8.6 \%$ with a mechanized peeling machine [16] Losses observed with the mechanical grater used in this study ranged between 2 and $5 \%$, which can be attributed to mash spillage from the hopper due to vibrations during cassava grating.

Losses at the dewatering stage are caused by the removal of the cyanide dissolved water and starch from the mash. The amount of expressed water is relative to the moisture content of the cassava tuber, which is a function of maturity ages. At this stage, lesser losses tend to correspond to cassava age of lesser moisture content. Cassava roots of 15 months age of maturity with higher dry matter accumulation and lower moisture content had lower dewatering losses compared to those harvested early. This result showed consistently higher dewatering losses for cassava harvested at 12 months age of maturity than corresponding 15 months cassava age, while 9 months age of cassava has the least. This may be due to duration of planting and variations in seasons of harvest. As noted by Hahn [17] during the rainy season, the dry matter content

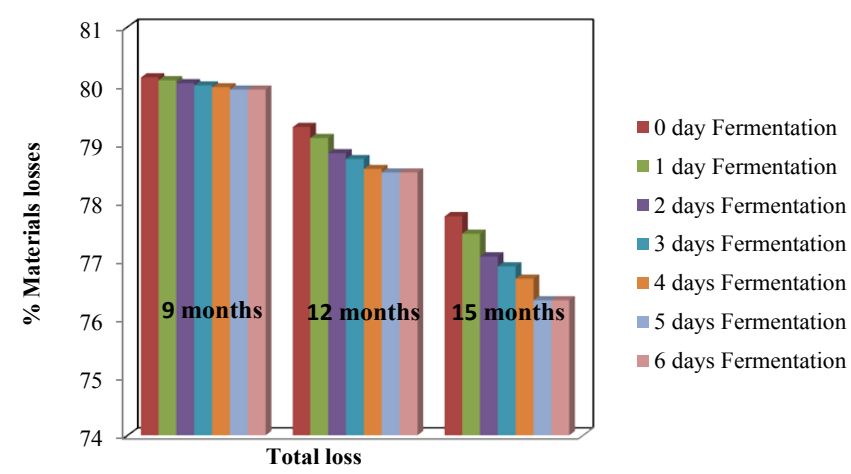

Figure 7: Estimated \% total losses at different ages of cassava and fermentation days.

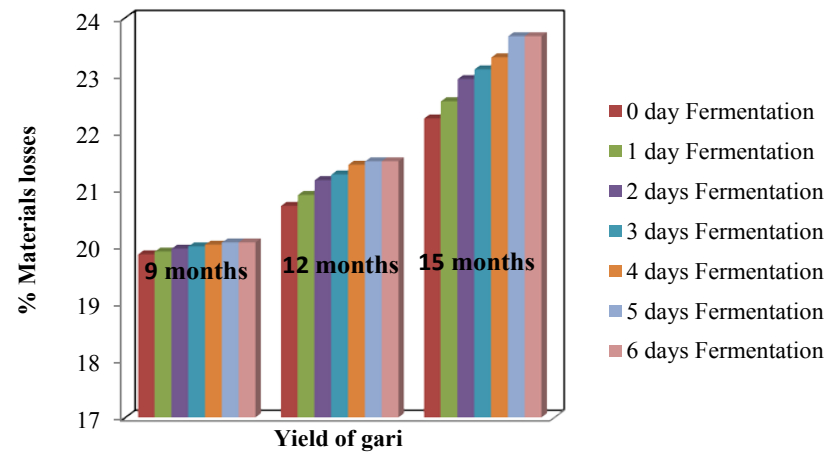

Figure 8: Estimated \% yield of gari at different ages of cassava and fermentation days. 

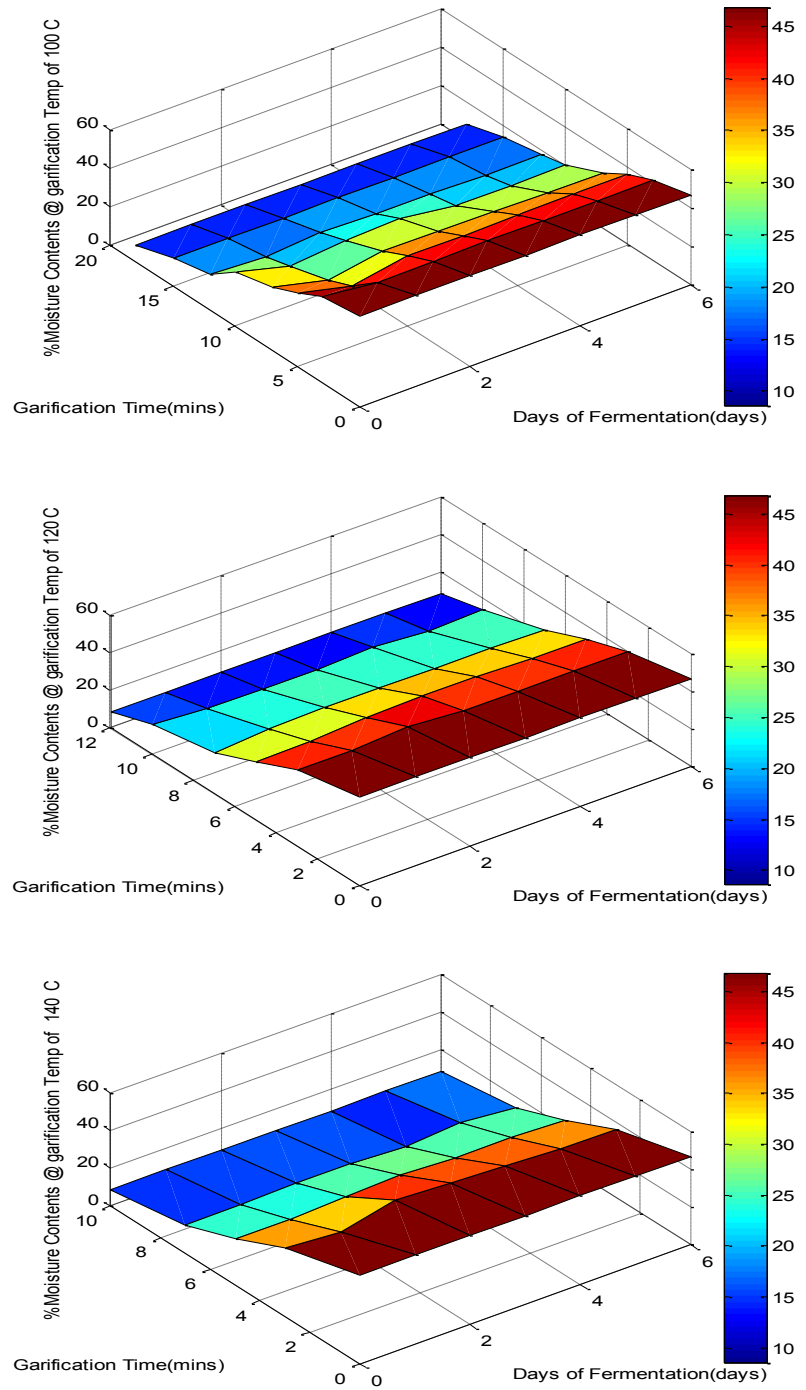

Figure 9: Surface plot of effect of cassava root processing variables on moisture content from 9 months age of maturity.

of roots is lower compared to the dry season. During growth season, both starch and roots production rapidly increases with moisture content to their maximum after which they decline afterwards [3]. The duration of fermentation showed slightly significant effect $(\mathrm{p} \leq$ 0.05 ) on the moisture content at different processing stages of the gari. According to Achinewhu, et al. [12], fermentation could play a vital role in the processing of gari during which linamarin is hydrolyzed to hydrocyanic acid to a level that may become harmless after garifying.

Sifting losses are much more associated with the skill of the processor to ensure reduced spillage while garification losses are dependent on garification temperature and moisture content before garifying. Cassava roots of 15 months age of maturity produced higher yields of gari than other maturity ages harvested earlier. This may be accounted for as a result of vascular woodiness of the roots as observed from the higher dry matter and relatively lower moisture content in the older roots. The mean yield of gari associated with the gari processing system from the ages of cassava used in this study ranged from 19.86 to $23.68 \%$, with average of about $21.77 \%$ of the initial weight of fresh cassava tubers $[17,18]$. This translates into a mean garification conversion rate of $0.22(\mathrm{wt} / \mathrm{wt})$, which was achieved using a locally fabricated electro-mechanical gari roaster. A comparable garification rate index of 0.23 had been reported in the literature by Amoah, et al. [14]. Since, the cassava tubers harvested at different maturity ages were passed through the set of equipment and processing methods, it may be presumed that the effects of maturity ages of cassava tubers and fermentation periods on the garification conversion rate were neutralized by each other. Therefore, the average garification rate index of 0.22 can posited to represent the efficacy of the processing system adopted in this study. This can be applied as a numerical index and bench mark for comparison of the efficacy of diverse garification processing systems for gari production. Hence, the higher the garification index of a system, the higher the potential yield of gari.

\section{Conclusions}

Cassava tubers of 15 months maturity age generally produced higher yields of gari than those harvested earlier. The garification rate or index achieved was estimated to be averagely 0.22 , which can be used as a numerical index and a bench mark for the determination of garification processing systems for gari production. The study also confirmed that the factors accounting for material losses are age of
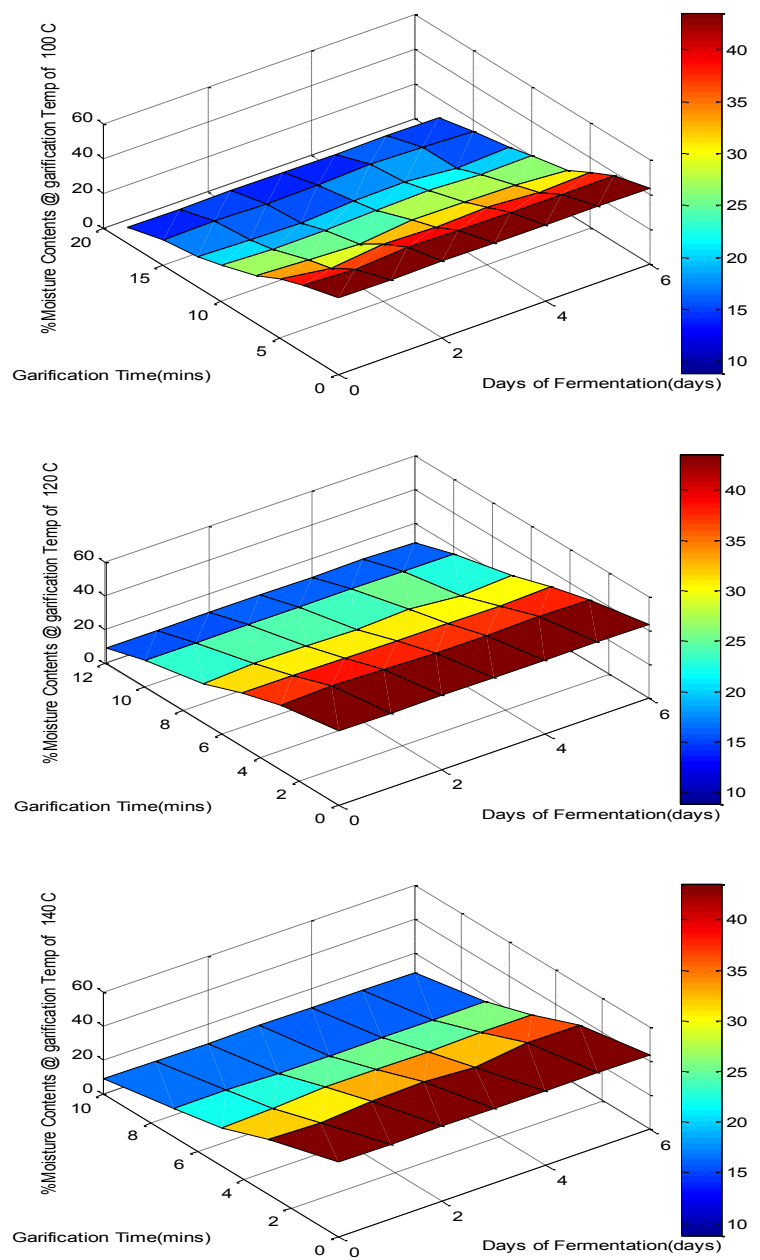

Figure 10: Surface plot of effect of cassava root processing variables on moisture content from 12 months age of maturity. 
Citation: Sobowale SS, Awonorin SO, Shittu TA, Oke MO, Adebo OA (2016) Estimation of Material Losses and the Effects of Cassava at Different Maturity Stages on Garification Index. J Food Process Technol 7: 554. doi:10.4172/2157-7110.1000554

Page 5 of 5
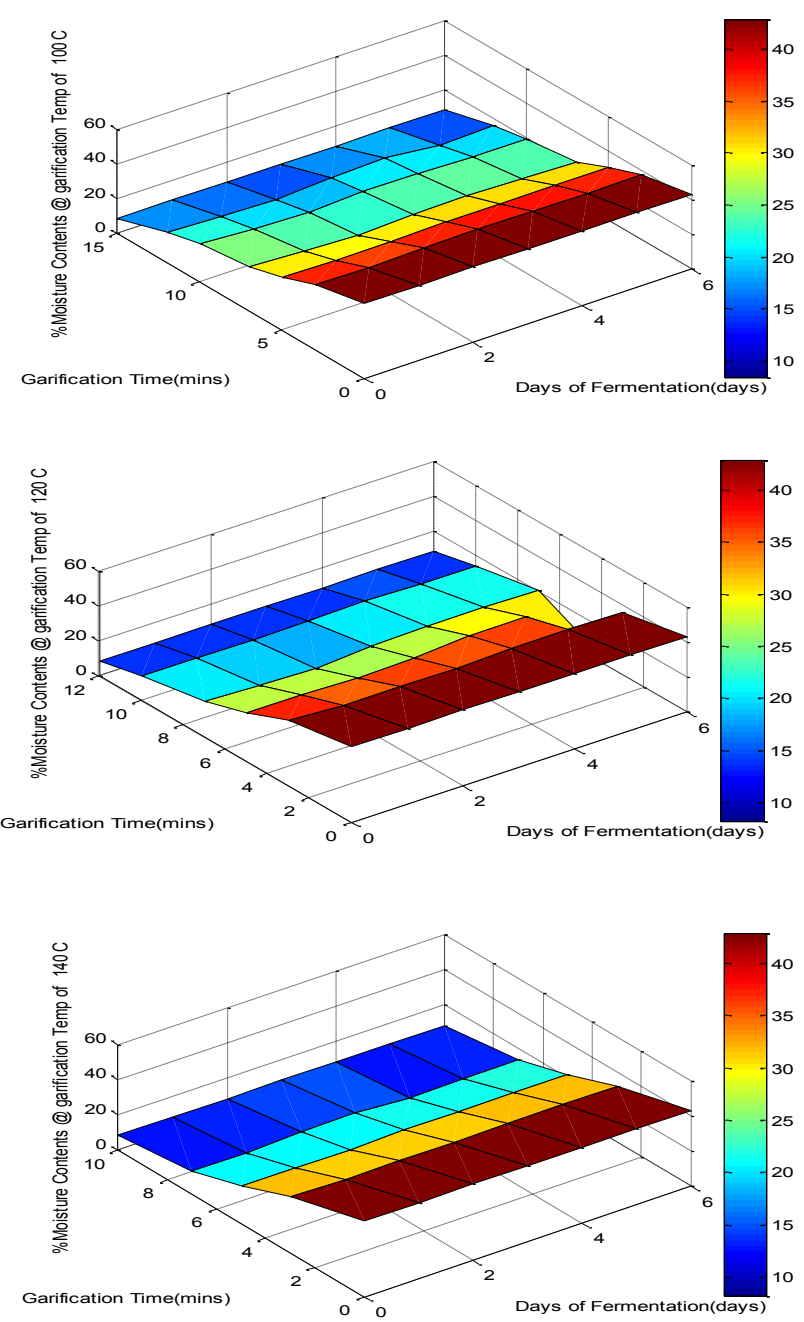

Figure 11: Surface plot of effect of cassava root processing variables on moisture content from 15 months age of maturity.

cassava at point of harvest and processing methods. The highest losses recorded were at the peeling, dewatering/fermentation and garification stages, while the least recorded losses were during the grating and sieving stages. Therefore, improved and increased gari yield should focus on the development and utilization of cassava tuber varieties with lesser peels and moisture content. These are important considerations to obtain an appreciable yield and quality gari for feasible commercial production.

\section{References}

1. Nwosu K (2006) Cassava Production, Proceedings of a workshop on electronics Application to information management, held at National Root Crops Research Institute (NRCRI), Umudike, Nigeria.

2. Asiedu JJ (1989) Processing tropical crops. A Technological Approach. Macmillian Press Ltd, London.

3. Opara LU (1999) Yam storage. In: CIGR Handbook of Agricultural Engineering Agro Processing, The American Society of Agricultural Engineers, St. Joseph, MI, USA.

4. NRCRI (19870 Briefs on research extension and teaching. National Root Crops Research Institute, (NRCRI), Umudike, Nigeria.

5. FAO (2006) Bankable investment project profile. Cassava Production, Processing and Marketing Project. Food and Agriculture Organization of the United Nation Rome.

6. Achinewhu SC, Barber LI, ljeoma IO (1998) Physicochemical properties and garification (gari yield) of selected cassava cultivars in Rivers State, Nigeria. Plant Foods Hum Nutr 52: 133-140.

7. Akingbala JO, Oyewole OB, Uzo-Peters PI, Karim RO, Baccus-Taylor GH, et al. (2005) Evaluating stored cassava quality in gari production. J Food Agric Environ 3: 75-80.

8. Amoah RS, Sam-Amoah LK, Adu BC, Duah F (2009) Estimation of the material losses and gari recovery rate during the processing of varieties and ages of cassava into gari. J Agric Res 5: 1-9.

9. Hahn SK (2006) An overview of traditional processing and utilization of Cassava in Africa.

10. Ingram JS, Humphries JRV (1972) Food crops of the lowland tropics. Oxford University Press, Oxford, London.

11. Jekayinfa SO, Olajide JO (2007) Analysis of energy usage in the production of three cassava-based foods in Nigeria. J Food Eng 82: 217-226.

12. Oduro I, Ellis WO (2000) Production of cassava and sweet potatoes based on snack food. Proposal Submitted to the Root and Tuber Improvement Programme, Ghana.

13. Owuamanam Cl, Iwouno JO, Ihediohanma NC, Barber LI (2010) Cyanide reduction, functional and sensory quality of gari as affected by $\mathrm{pH}$, temperature and fermentation time. Pakistan J Nutr 9: 980-986.

14. Sanni MO, Oluwabami AO (2003) The effect of cassava post-harvest and fermentation time on gari sensory qualities. Donald Danforth Plant Science Centre, Missouri, USA.

15. Sanni MO (1994) Garri processing in Ibadan metropolis: factors controlling quality at the small-scale level. Acta Hortic 380: 256-260.

16. Sobowale SS, Adebiyi JA, Adebo OA (2015) Design and performance evaluation of a melon sheller. J Food Proc Eng.

17. Steel RGD, Torrie JH (1980) Principle and procedure of statistics, Mc Grawhill, New York, USA.

18. Ukpabi UJ, Ndimele C (1990) Evaluation of the quality of gari produced in Imo state. Nig Food J 8: 105-109. 